\title{
CHEMODNERVATION FOR CERVICAL DYSTONIA: A CLINICAL REVIEW
}

\author{
Muhammad Atif Ameer ${ }^{1 \otimes}$, Danish Bhatti'
}

\begin{abstract}
Cervical dystonia (CD) is a focal dystonia characterized by involuntary contractions of neck muscles that result in patterned movements and abnormal postures of the head and neck that have a directional quality. CD is the most common form of dystonia presenting to the movement disorders clinic. Botulinum toxin is an effective treatment for cervical dystonia. It has become the first-line treatment for cervical dystonia with a satisfactory relief of symptoms reported in more than $80 \%$ of the cases. Multiple small and large scale studies proven that fact and provided Class-A evidence for the benefit. However, $20 \%$ of the patients discontinue treatment due to adverse effects, treatment failure and other reasons. With the proper knowledge of toxins and the anatomy of the neck, much better results can be achieved with fewer and self-limiting adverse effects as compared to other modalities. However, the expert consensus recommendations are lacking to guide clinicians for optimal use of botulinum toxin for cervical dystonias. This paper discusses the different available treatments, botulinum injection techniques and the adverse effects involved with the procedure.
\end{abstract}

KEY WORDS: Cervical Dystonia (MeSH); Torticollis (MeSH); Chemodenervation (MeSH); Nerve Block (MeSH); Botulinum Toxins (MeSH); Movement Disorders (MeSH).

THIS ARTICLE MAY BE CITED AS: Ameer MA, Bhatti D. Chemodnervation for cervical dystonia: a clinical review. Khyber Med Univ J 2020; I2(3):253-8. DOI: 10.35845/kmuj.2020.20478.

\section{INTRODUCTION}

$\mathrm{D}$ ystonia is a syndrome in which sustained involuntary muscle contraction occurs, which frequently causes twisting and repetitive movements along with abnormal posturing. It can affect any part of the body and is thus named based on the region involved, such as cervical dystonia involving the muscles of the neck. The involvement of one area of the body is called focal dystonia, while the involvement of few areas as segmental (continuing areas) or multifocal (non-continuing areas). The involvement of one side is termed hemidystonia, and of more than 3 areas involved is termed as generalized dystonia.

The treatment of dystonia is usually symptomatic unless a secondary underlying cause is identified, which can be treated. Symptomatic treatment regime includes pharmacotherapies (anticholinergic medications, dopaminergic depleting agents and muscle relaxants), physical therapy, supportive therapy, deep brain stimulation surgery (DBS) or chemodenervation using botulinum toxin (BoNT).

Chemodenervation with BoNT is considered the treatment of choice for most focal dystonia. BoNT provides its beneficial effect by inhibiting the release of acetylcholine into the neuromuscular junction and consequently weakens the muscle over the period. BoNT injections were initiated as a treatment for CD in the mid-1980s' and multiple large, controlled studies have provided Class A evidence for the benefit. ${ }^{2-5}$ Deep brain stimulation surgery (DBS) is an invasive procedure and usually reserved for patients who fail the medical treatments.

BoNT injections are a very effective treatment for $C D$ if administered by a clinician with expertise in the disorder,
I. Department of Neurological Sciences, University of Nebraska Medical Center, Omaha, NE USA.

Email凶:dr.atifameer@outlook.com

Contact \#: + I-917-774-5368

$\begin{array}{ll}\text { Date Submitted: } & \text { June 06, } 2020 \\ \text { Date Revised: } & \text { September 02, 2020 } \\ \text { Date Accepted: } & \text { September 07, 2020 }\end{array}$

an excellent familiarity of the functional anatomy of the neck, knowledge of the brands and serotypes of BoNT, an understanding of the technical issues related to injection, and an awareness of the potential adverse effects. This article provides a brief review of the available evidence and effectiveness of the therapy as well as providing some practical information for adapting this therapy in practice.

\section{METHODS}

A comprehensive search of databases and search engines, including PubMed, Google Scholar and Medline was performed using keywords cervical dystonia, BoNT, botulinum toxin, and chemodenervation. Interventional and review articles with the potential of contributing to chemodenervation of cervical dystonia were included in the review. The information gathered from the literature search was integrated with clinical expertise and presented as a comprehensive guideline to assist the clinical practice involving chemodenervation of CD.

\section{DISCUSSION}

Overview of Cervical Dystonia: Cervical dystonia (CD) is a focal dystonia characterized by involuntary contractions of neck muscles that result in patterned movements and abnormal postures of the head and neck that have a directional quality. ${ }^{6}$ There may be overlying spasms of the muscles that cause overlying jerky movements or tremors in over half the patients. ${ }^{7}$ 
TABLE I: BOTULINUM TOXINS CURRENTLY APPROVED IN UNITED STATES

\begin{tabular}{|c|c|c|c|c|}
\hline Toxin Name & $\begin{array}{l}\text { Onabotulinumtoxin A } \\
\text { (ONA-BoNTA) }\end{array}$ & $\begin{array}{l}\text { Rimabotulinumtoxin B } \\
\text { (RIMA-BoNTB) }\end{array}$ & $\begin{array}{c}\text { Abobotulinumtoxin A } \\
\text { (ABO-BoNTA) }\end{array}$ & $\begin{array}{l}\text { Incobotulinumtoxin A } \\
\text { (INCO-BoNTA) }\end{array}$ \\
\hline Brand Name & BOTOX $®$ & MYOBLOC $\AA$ & DYSPORT ${ }^{\circledR}$ & XEOMIN ${ }^{\circledR}$ \\
\hline Serotype & A & B & A & A \\
\hline Vial sizes & $\begin{array}{c}50 \\
100 \\
200\end{array}$ & $\begin{array}{c}2,500 \\
5,000 \\
10,000\end{array}$ & $\begin{array}{l}300 \\
500\end{array}$ & $\begin{array}{c}50 \\
100\end{array}$ \\
\hline Dose range for cervical dystonia & $100-300$ & $2,500-15,000$ & $500-1000$ & $120-240$ \\
\hline
\end{tabular}

The majority of the patients of cervical dystonia presents with the combination of neck rotation (Torticollis), extension (Reterocolis), flexion (Anetrocolis), or head tilt (Laterocolis) with or without sagittal shift. ${ }^{8}$ Patients with primary cervical dystonia have usually unremarkable history, and the majority of the patients have no secondary cause of dystonia except for the primary dystonic gene." Secondary cervical dystonia is caused by an alternate etiology such as central or peripheral trauma, neurodegenerative diseases (such as Parkinson's Disease), or exposure to dopamine receptor antagonists (Tardive dystonia).

$C D$ is the most common focal dystonia seen in an office setting. Despite this, it may take 4 years from symptom onset before diagnosis. ${ }^{10}$ Patients see a mean of 3.5 physicians, including neurologists, before diagnosis in the United States. From $65 \%-75 \%$ of CD patients experience pain associated with their dystonia. In those patients with isolated CD at the onset, approximately $23 \%$ will have spread of dystonia, most frequently to the arm." Although approximately $10 \%$ - $20 \%$ of patients may experience a partial or complete remission of symptoms, the condition often recurs within 5 years. It is estimated that less than $1 \%$ will have permanent remission. ${ }^{12}$

Cervical dystonia affects approximately 200,000 people in the United States. ${ }^{13}$ It occurs more frequently in women than men, with a usual age of onset in the fourth or fifth decade. Estimates of incidence in a multiethnic population are 0.80 per 100,000 persons per year, with the highest incidence in Caucasians, and a 2.5 times higher incidence in women than men. ${ }^{14}$
Overview of Botulinum Toxin: BoNT is approximately $150 \mathrm{kDa}$, produced as inactive single chain polypeptides and enzymatically activated to a double-chain molecule, consisting of a heavy and light chain; linked by a disulfide bond and a loop from the heavy chain that wraps around the light chain. ${ }^{15}$ The carboxy-terminal of the heavy chain $(\mathrm{Hcc})$ mediates binding to the presynaptic cholinergic nerve terminals and internalization of the toxin into the cell. ${ }^{16}$ The amino terminal of the heavy chain (Hcn) mediates translocation of the light chain into the cytosol through a process of unfolding of the light chain and chaperoning the light chain through a membrane channel into the cytosol. ${ }^{17}$ The light chain is responsible for the toxic effects, acting as a zincendopeptidase, cleaving specific proteins responsible for membrane fusion (SNARE complex).

Mechanism of Actions: There are seven distinct antigenic serotypes of botulinum toxin, A-G. The serotypes most associated with human disease are BoNT types A, B, and E. ${ }^{18}$ BoNT A, C, and $E$ cleave SNAP-25 (synaptosomalassociated protein 25 ), a membraneassociated protein. Serotypes B, D, F, and $G$ cleave Vesicular Associated Membrane Protein (VAMP), also called synaptobrevin. Type $C$ additionally cleaves Syntaxin, a membrane protein. $^{19,20}$

Ultimately, the action of BoNT is to interrupt transmission at the neuromuscular junction and, in effect, to denervate muscle. ${ }^{21,22}$ The onset of action is typically 5-7 days after the injections, and the effect persists for weeks to months (typically 2-3 months) with peak benefits around one month.
The duration of the effect may be somewhat dependent on serotype. ${ }^{23-26}$ The mechanism for this extended duration of action has been hypothesized to arise from either continued protease activity within the cell or persistent interference by cleaved substrate with normal membrane fusion. ${ }^{24}$ Currently, there is no known way to reverse the paralytic effects of BoNT after it has been internalized. Active and passive immunization can inactivate toxins only prior to internalization into the cell.

Commercial Preparations: BoNT is available in the United States as 2 serotypes ( $A$ and $B$ ) and 4 brands (Table I). The toxin is biologically active and cannot be measured in weight like $\mathrm{mg}$. It is measured in mouse units: I mouse unit equals the LD 50 median dose for peritoneal injection for a particular size, sex, and breed of the mouse, e.g., $30 \mathrm{~g}$ females Webster mouse. Therefore, the potency and recommended dose unit for each serotype in a commercially available dose are unique. There are no established dosing equivalencies. An evidence-based review of the efficacy and safety of these available botulinum toxins in neurological disorders was published in $2008^{2}$, and updated in 2016 with newer evidence. ${ }^{27}$

Chemodenervation for Cervical Dystonia: Although not a degenerative disease, the $C D$ is a chronic neurological condition that has no curative treatment. There are several approaches to reduce symptoms. Physiotherapy may be useful as an adjunct treatment, with some reports of benefit, although adequate controlled trials are lacking. ${ }^{28}$ There are no oral medications that are approved by the Food and Drug Administration for use in 
cervical dystonia. However, several agents, including levodopa, anticholinergic agents, baclofen, clonazepam, tetrabenazine, and a variety of muscle relaxants and anticonvulsants have tried with anecdotal reports of benefit. ${ }^{29,30}$

The current state of Evidence: Seven Level-I studies have established BoNT as an effective and safe treatment for cervical dystonia. ${ }^{27}$

a. A Level-I study found that IncoBoNT-A in two doses (I $20 \mathrm{U}$ or $240 \mathrm{U}$ ) improved cervical dystonia from baseline to week 4 (p, $0.00 \mathrm{I}$ ) as measured by the Toronto Western Spasmodic Torticollis Rating Scale (TWSTRS).

b. Two Level-I studies randomized patients with $C D$ to OnaBoNT-A $(150-250 \mathrm{U})$ or RimaBoNT-B $(10,000 \mathrm{U})$ and noted similar durations of effect and no significant difference in improved on Toronto Western Spasmodic Torticollis Rating Scale (TWSTRS) scores at 4 weeks. Dysphagia occurred more frequently in the RimaBoNT-B group in both studies (48\% vs. $19 \%$ in the first study and $16 \%$ vs. $14.5 \%$ in the second study). ${ }^{25,26}$

c. Level-I study compared the effect of OnaBoNT-A $70 \cup-240 U$ with AboBoNT-A $240 \cup-720 \cup$ and observed no difference in the impairment of post-treatmentTsui (used for the assessment of the extent and duration of impairment in patients with cervical dystonia) scores at 4 weeks. ${ }^{32}$

d. Three long-term, prospective, open-label studies (LevelIV)evaluated the clinical response of repeated injections of OnaBoNT-A and found persistent benefit for up to 2 years. ${ }^{27}$

Injection Techniques: Because the effect of botulinum toxin is to weaken the muscle, the overall principle when injecting the toxin is to know the functional anatomy of the neck and identify the particular muscles that are involved in the dystonic posture. Head postures associated with cervical dystonia include: a. A horizontal turn (torticollis)

b. Lateral flexion of the head to the shoulder (laterocollis)

c. Forward flexion of the head with the chin deviated downward (anterocollis)

d. A posterior extension of the head (retrocollis)

e. A forward or backward shift of the head on the shoulders (sagittal shift)

f. A lateral shift of the head on the shoulders (lateral shift).

In most patients, the head posture of their $C D$ is complicated, combining movement along several axes of head posture. Each posture is associated with dystonic activation of particular muscles. The most frequently injected muscles include $\mathrm{the}$ sternocleidomastoid, splenius capitis or cervices, trapezius, levator scapulae, longissimus capitis or cervices, scalene complex. BoNT injections begin to have effected a few days after injection, with peak effect around 4 weeks followed by a waning effect at approximately 3 months.

There are many unanswered technical issues related to the Injection of BoNT. These include the number of injection sites per individual muscle, dilution of each brand of botulinum toxin, and the use of electromyography. There are no studies available that adequately address these issues. The role of electromyography is controversial, with one study demonstrating an increased magnitude of improvement when a muscle is targeted by EMG activity ${ }^{33}$, but no confirmatory studies have been done. $^{25,26}$

Currently, there is no evidence to indicate that one brand or serotype is superior to another. In patients who have developed secondary, antibodymediated resistance to the effects of serotype A may benefit from serotype $B .{ }^{34}$ However, it is essential to recognize that the dosing of serotype $B$ should be based on the starting doses for that serotype without the use of any type of conversion factor. The lack of a dosing equivalency is also recognized for the different brands of serotype A. If a patient is currently being treated with one brand, the dose of another brand cannot be determined from previous doses.

Adverse Effects and Clinical pearls: The adverse effects arising from botulinum toxin injections for cervical dystonia are usually related to the spread of toxin from the injected muscle. The most common side effects noted in the trials include pain at the injection site, dysphagia, and neck weakness, sometimes associated with pain. ${ }^{35}$

The injection site pain is the most common reported adverse effect and is seen in up to $30 \%$ of the patients in clinical practice (similar to some studies reported). ${ }^{36}$ The pain is usually mild, localized to the injection site, and not associated with any skin reaction or abscess. Usually, it does not require any treatments, but over the counter medications such as acetaminophen can be used as well as hot compresses or massage. The pain is typically selflimiting and lasting mostly less than 3 days; however, prolonged pain for weeks can be rarely seen. It is not typically associated with the injection techniques, but Rima-BoNT-B is more likely to cause local pain as the storage solution is acidic with a $\mathrm{pH}$ of less than $7^{37}$

Dysphagia is one of the most commonly reported adverse effects. It has been reported in as much as $30 \%$ of the injected patients in the earlier studies, with current rates much lower (10$15 \%)$. Most often, dysphagia is very mild to minimal, not affecting a patient's oral nutrition intake and more of a nuisance and usually last few days to around 2 weeks. The most widely cited factor is the dosage and placement of the BoNT injections into anterior muscles, including the sternocleidomastoid, scalene complex, and digastrics muscles located under the chin. ${ }^{38,39}$ There have been very few patients with severe dysphagia requiring temporary nasogastric feeding. Some injection techniques have been proposed by experts to avoid this side effect (such as higher injection placement). Once it starts, only 
conservative treatment can be provided, and it has to run its course without any specific treatment to reverse it.

Neck weakness begins around I-2 weeks after injection and may present as neck pain that differs from the dystonic pain. Patients will note that they have difficulty lifting their head from the pillow, or a sense that the head is unstable or will droop when bending forward. The risk is reported to be $10 \%-20 \%$ in the studies but again with a wide range of severity, with most patients not functionally affected by it but few patients requiring supportive treatment with neck braces until this wears off. ${ }^{41}$ More severe weakness tends to last longer in duration. An underlying weakness of the muscles that were injected must be ruled out (such as myopathy).

Response to Chemodenervation: Because $C D$ is a life-time condition, and BoNT effects are transient, CD patients will require repeated injections at approximately 3-4 month intervals. Some patients will never benefit from injections and are called primary nonresponders. This occurs most frequently in patients with structural abnormalities, such as contractures, or those with predominant anterocollis, in which the muscles are not safely accessible for injection. ${ }^{42,43}$ A secondary non-response is defined as the loss of benefit after a good initial response to a series of prior injections. Common causes for secondary non-response include injection of the wrong muscles, inadequate dosing, or unrealistic patient expectation. Repeated exposure to a foreign protein such as BoNT may give rise to the development of neutralizing antibodies. $^{44}$

\section{CONCLUSION}

Cervical Dystonia is the most common form of focal dystonia and is a very disabling and painful condition affecting the quality of life. Chemodenervation with botulinum toxin injections is the most effective and established therapy for $C D$. Their use requires careful planning and familiarity with adverse effects to avoid complications and to get patients successful therapies.

\section{REFERENCES}

I. Tsui J, Eisen A, Mak E, Carruthers J, Scott A, Calne D. A pilot study on the use of botulinum toxin in spasmodic torticollis. Can J Neurol Sci 1985;12(4):3|4-6. DOI: 10. I0I7/S031716710003540X.

2. Simpson D, Blitzer A, Brashear A, Comella C, Dubinsky R, Hallett M, et al. Assessment: Botulinum neurotoxin for the treatment of movement disorders (an evidencebased review): report of the Therapeutics and Technology Assessment Subcommittee of the American Academy of Neurology. Neurology 2008;70(19): 1699-706. DOI: I0.I2I2/0I.wnl.00003| | 389 . $26 \mid 45.95$.

3. Comella CL, Jankovic J, Truong DD, Hanschmann A, Grafe S, U.S. XEOMIN Cervical Dystonia Study Group. Efficacy and safety of incobotulinumtoxinA (NT 20I, $X E O M I N{ }^{\circledR}$, botulinum neurotoxin type $A$, without accessory proteins) in patients with cervical dystonia. J Neurol Sci 201 I;308(I-2):103-9. DOI: I0.1016/j.jns.20II.05.04I.

4. Truong $D$, Brodsky M, Lew $M$, Brashear A, Jankovic J, Molho E, et al. Long-term efficacy and safety of botulinum toxin type $A$ (Dysport) in cervical dystonia. Parkinsonism Relat Disord 2010;16(5):316-23. DOI: 10.1016/j.parkreldis.2010.03. 002.

5. Charles D, Brashear A, Hauser RA, Li H, Boo L, Brin MF, et al. Efficacy, tolerability, and immunogenicity of onabotulinumtoxina in a randomized, double-blind, placebocontrolled trial for cervical dystonia. Clin Neuropharmacol 20I2;35(5): 208-I4. DOI: 10.1097/WNF.0b013 e3।826538c7.

6. Jankovic J, Leder S, Warner D, Schwartz K. Cervical dystonia: clinical findings and associated movement disorders. Neurology | 99|;4|(7): |088-9|. DOI: I0.1212/ wnl.4I.7.1088.

7. Chan J, Brin MF, Fahn S. Idiopathic cervical dystonia: clinical characteristics. Mov Disord 1991;6
(2):I|9-26. DOI: $10.1002 / \mathrm{mds}$ 870060206.

8. Velickovic M, Benabou R, Brin MF Cervical dystonia. Drugs 200I;6I (I3): | 92I-43. DOI: $10.2165 / 00003495-200161130$ 00004.

9. Klein C, Lohmann K, Marras C, Münchau A. Hereditary dystonia overview. GeneReviews ${ }^{\circledR}$ [Internet]: University of Washington, Seattle;2017. [Accessed on: May 25, 2020]. Available from URL: https://www. ncbi.nlm.nih.gov/books/NBKII55/.

10. Tiderington E, Goodman EM, Rosen AR, Hapner ER, Johns III MM, Evatt $M L$, et al. How long does it take to diagnose cervical dystonia? J Neurol Sci 20I3;335(I-2):72-4. DOI: 10.1016/j.jns.2013.08.028.

Il.Abbruzzese G, Berardelli A, Girlanda P, Marchese R, Martino D, Morgante $F$, et al. Long-term assessment of the risk of spread in primary late-onset focal dystonia. J Neurol Neurosurg Psychiatry 2008;79(4):392-6. DOI. 10.1 136/jnnp.2007.124594.

12. Dauer WT, Burke RE, Greene P, Fahn S. Current concepts on the clinical features, aetiology and management of idiopathic cervical dystonia. Brain 1998;121(4):54760. DOI: I0.1093/brain/I21.4.547.

13. Claypool DW, Duane DD, Ilstrup DM, Melton III LJ. Epidemiology and outcome of cervical dystonia (spasmodic torticollis) in Rochester, Minnesota. Mov Disord 1995; 10 (5):608-I4. DOI: $10.1002 / \mathrm{mds}$. 870100513 .

14. Marras C, Van den Eeden S, Fross R, Benedict-Albers K, Klingman J, Leimpeter $A$, et al. Minimum incidence of primary cervical dystonia in a multiethnic health care population. Neurology 2007;69(7): 676-80. DOI: |0.12|2/0|.wnl.0000 267425.5I598.c9.

I5. Montal M. Botulinum neurotoxin: a marvel of protein design. Annu Rev Biochem 2010;79:59I-6I7. DOI: 10.1|46/annurev.biochem.051908. 125345. 
16. Peng Chen Z, Morris JG, Rodriguez RL, Shukla AW, Tapia-Núñez J, Okun MS. Emerging opportunities for serotypes of botulinum neurotoxins. Toxins 2012;4 (II):II96-222. DOI: 10.3390/ toxins 4111196

17. Fischer A, Sambashivan S, Brunger AT, Montal M. Beltless translocation domain of botulinum neurotoxin $A$ embodies a minimum ionconductive channel. J Biol Chem 20I2;287(3):|657-6I. DOI: 10. I074/jbc.CI | I.319400.

18. Shapiro RL, Hatheway C, Swerdlow DL. Botulism in the United States: a clinical and epidemiologic review. Ann Inter Med 1998; I29(3):22I-8. DOI: 10.7326/0003-48|9-129-3199808010-0001 I.

19. Schiavo G, Rossetto O, Benfenati F, Poulain B, Montecucco C. Tetanus and Botulinum Neurotoxins Are Zinc Proteases Specific for Components of the Neuroexocytosis Apparatus a. Ann N Y Acad Sci 1994;7I0(I):65-75. DOI: $10.1 \mathrm{III/j} .1749-6632.1994$. tb266|4.x.

20. Blasi J, Chapman ER, Link E, Binz T, Yamasaki S, De Camilli $P$, et al. Botulinum neurotoxin A selectively cleaves the synaptic protein SNAP25. Nature 1993;365(6442): 160-3. DOI: $10.1038 / 365 \mid 60 \mathrm{a} 0$.

21. Montecucco C, Schiavo G. Structure and function of tetanus and botulinum neurotoxins. Q Rev Biophys 1995;28(4):423-72. DOI: 10.1017/s0033583500003292.

22. Montecucco C, Schiavo G, Rossetto O. The Mechanism of Action of Tetanus and Botulinum Neurotoxins. In: Seiler JP, Kroftová O, Eybl V (eds). Toxicology - From Cells to Man. Archives of Toxicology (Supplement), 1996; Vol 18:pp34254. Springer, Berlin, Heidelberg. DOI: 10.1007/978-3-642-6। I05-6 32.

23. Sloop RR, Cole BA, Escutin RO. Human response to botulinum toxin injection: type B compared with type A. Neurology 1997;49(I): 18994. DOI: 10.1212/wnl.49.1.189.
24. Dolly O. Synaptic transmission: inhibition of neurotransmitter release by botulinum toxins. Headache 2003;43:16-24. DOI: 10.1046/j. I526-46|0.43.7s.4.x.

25. Comella C, Jankovic J, Shannon K, Tsui J, Swenson M, Leurgans S, et al. Comparison of botulinum toxin serotypes $A$ and $B$ for the treatment of cervical dystonia. Neurology 2005;65(9): | 1423-9. DOI: I0.12/2/ 0I.wnl.0000।83055.8I056.5c

26. Pappert E, Germanson T, Myobloc/Neurobloc European Cervical Dystonia Study Group. Botulinum toxin type $B$ vs. type $A$ in toxin-naive patients with cervical dystonia: randomized, doubleblind, noninferiority trial. Mov Disord 2008;23(4):5 I0-7. DOI: 10.1002/mds.21724.

27. Simpson DM, Hallett M, Ashman EJ, Comella CL, Green MW, Gronseth GS, et al. Practice guideline update summary: Botulinum neurotoxin for the treatment of blepharospasm, cervical dystonia, adult spasticity, and headache: Report of the Guideline Development Subcommittee of the American Academy of Neurology. Neurology 2016;86(19):1818-26. DOI: 10. I 21 2/WNL.0000000000002560.

28. De Pauw J, Van der Velden K, Meirte J, Van Daele U, Truijen S, Cras P, et al. The effectiveness of physiotherapy for cervical dystonia: a systematic literature review. J Neurol 20I4;26I ( I0): I857-65. DOI: I0.1007/s004|5-0|3-7220-8.

29. Balash Y, Giladi N. Efficacy of pharmacological treatment of dystonia: evidence-based review including meta-analysis of the effect of botulinum toxin and other cure options. Eur J Neurol 2004; II (6):36I-70. DOI: 10.11 II/j.I468|331.2004.00845.x

30. Kenney C, Hunter C, Jankovic J. Long-term tolerability of tetrabenazine in the treatment of hyperkinetic movement disorders. Mov Disord 2007;22(2):193-7. DOI: 10.1002/mds.2I 222.

31. Comella C, Jankovic J, Truong D, Hanschmann A, Grafe S, US
XEOMIN Cervical Dystonia Study Group. Efficacy and safety of incobotulinumtoxinA (NT 20I, XEOMIN ${ }^{\circledR}$, botulinum neurotoxin type $A$, without accessory proteins) in patients with cervical dystonia. Neurol Sci 201 I;308(I-2): 103-9. DOI: I0.1016/j.jns.20II.05.04I.

32. Odergren $\mathrm{T}$, Hjaltason $\mathrm{H}$, Kaakkola S, Solders G, Hanko J, Fehling C, et al. A double blind, randomised, parallel group study to investigate the dose equivalence of Dysport ${ }^{\circledR}$ and Botox ${ }^{\circledR}$ in the treatment of cervical dystonia. J Neurol Neurosurg Psychiatry 1998; 64(I):6-12. DOI: 10.1136/jnnp. 64.1.6.

33. Comella CL, Buchman AS, Tanner CM, Brown-Toms NC, Goetz CG. Botulinum toxin injection for spasmodic torticollis: increased magnitude of benefit with electromyographic assistance. Neurology 1992;42(4):878-82. DOI: $|0.12| 2 / w n \mid .42 .4 .878$.

34. Brin M, Lew M, Adler CH, Comella C, Factor S, Jankovic J, et al. Safety and efficacy of NeuroBloc (botulinum toxin type B) in type A-resistant cervical dystonia. Neurology 1999;53(7): |431-8. DOI: |0.12|2/wnl.53.7.|43| .

35. Ramirez-Castaneda J, Jankovic J. Long-term efficacy and safety of botulinum toxin injections in dystonia. Toxins (Basel) 20I3;5(2):249-66. DOI: 10.3390/ toxins 5020249 .

36. Contarino MF, Van Den Dool J, Balash Y, Bhatia K, Giladi N, Koelman JH, et al. Clinical practice: evidence-based recommendations for the treatment of cervical dystonia with botulinum toxin. Front Neurol 2017;8:35. DOI: 10.3389/fneur.2017.00035.

37. Pavone F, Luvisetto S. Botulinum neurotoxin for pain management: insights from animal models. Toxins (Basel) 20I0;2(I2):2890-9|3. DOI: 10.3390/toxins2 22890 .

38. Borodic GE, Joseph M, Fay L, Cozzolino D, Ferrante RJ. Botulinum $A$ toxin for the treatment of spasmodic torticollis: dysphagia 
and regional toxin spread. Head Neck 1990; I 2(5):392-9. DOI: 10.1002/hed.2880I 20504.

39. Kutschenko A, Klietz M, Paracka L, Kollewe K, Schulte-Sutum A, Janssen $T$, et al. Dysphagia in cervical dystonia patients receiving optimised botulinum toxin therapy: a single-center retrospective cohort study. J Neural Transm (Vienna) 2020; | 27(8): I |6I-5. DOI: |0. I007| s00702-020-02220-z.

40. Jinnah $H$, Goodmann E, Rosen AR, Evatt $M$, Freeman $A$, Factor $S$. Botulinum toxin treatment failures in cervical dystonia: causes, management, and outcomes. J Neurol 2016;263(6): I I88-94. DOI: 10.1007/s004|5-0|6-8|36-x.

4I. Mustalampi S, Ylinen J, Korniloff K, Weir A, Häkkinen A. Reduced Neck Muscle Strength and Altered Muscle Mechanical Properties in Cervical Dystonia Following Botulinum Neurotoxin Injections: A Prospective Study. J Mov Disord 2016;9(I):44-9. DOI: 10.14802/ jmd. I5035.

42. Comella $C$. The treatment of cervical dystonia with botulinum toxins. J Neural Transm 2008; II5(4):579-83. DOI. |0.1007/s00702-007-083 |-4.

43. Papapetropoulos S, Tuchman A, Sengun C, Russell A, Mitsi G, Singer C. Anterocollis: clinical features and treatment options. Med Sci Monit 2008; 14(9):CR427-30.

44. Kessler KR, Skutta M, Benecke R. Long-term treatment of cervical dystonia with botulinum toxin $A$ : efficacy, safety, and antibody frequency. German Dystonia Study Group. J Neurol 1999;246(4):26574. DOI: I0.1007/s004 I50050345.

\section{AUTHORS' CONTRIBUTIONS}

Following authors have made substantial contributions to the manuscript as under:

MAA: Searching and summarizing the literature, drafting the manuscript, final approval of the version to be published

DB: Conceiving of idea, searching and summarizing the literature, drafting the manuscript and critical revision of the manuscript, final approval of the version to be published

Authors agree to be accountable for all aspects of the work in ensuring that questions related to the accuracy or integrity of any part of the work are appropriately investigated and resolved.

\section{CONFLICT OF INTEREST \\ Authors declared no conflict of interest GRANT SUPPORT AND FINANCIAL DISCLOSURE NIL}

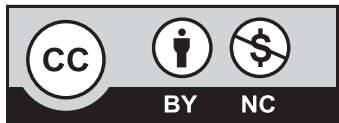

This is an Open Access article distributed under the terms of the Creative Commons Attribution-Non Commercial 2.0 Generic License.

\section{KMUJ web address: www.kmuj.kmu.edu.pk}

Email address: kmuj@kmu.edu.pk 